\title{
ZnO Coatings with Controlled Pore Size, Crystallinity and Electrical Conductivity
}

\author{
Roman SCHMACK ${ }^{1}$, Björn ECKHARDT ${ }^{1}$, Gregor KOCH $^{2}$, Erik ORTEL ${ }^{3}$, \\ Ralph KRAEHNERT ${ }^{1 *}$
}

\author{
${ }^{1}$ Technische Universität Berlin, Department of Chemistry, Strasse des 17. Juni 124, D-10623 Berlin, Germany \\ ${ }^{2}$ Technische Universität Berlin, Department of Chemistry, Strasse des 17. Juni 115, D-10623 Berlin, Germany \\ ${ }^{3}$ BAM - Federal Institute for Materials Research and Testing, Division 6.8, Unter den Eichen 44-46, DE-12203 Berlin \\ cross ${ }^{\text {ref }}$ http://dx.doi.org/10.5755/j01.ms.22.1.8634
}

Received 07 November 2014; accepted 08 March 2015

\begin{abstract}
Zinc oxide is a wide bandgap semiconductor with unique optical, electrical and catalytic properties. Many of its practical applications rely on the materials pore structure, crystallinity and electrical conductivity. We report a synthesis method for $\mathrm{ZnO}$ films with ordered mesopore structure and tuneable crystallinity and electrical conductivity. The synthesis relies on dip-coating of solutions containing micelles of an amphiphilic block copolymer and complexes of $\mathrm{Zn}^{2+}$ ions with aliphatic ligands. A subsequent calcination at $400{ }^{\circ} \mathrm{C}$ removes the template and induces crystallization of the pore walls. The pore structure is controlled by the template polymer, whereas the aliphatic ligands control the crystallinity of the pore walls. Complexes with a higher thermal stability result in $\mathrm{ZnO}$ films with a higher content of residual carbon, smaller $\mathrm{ZnO}$ crystals and therefore lower electrical conductivity. The paper discusses the ability of different types of ligands to assist in the synthesis of mesoporous $\mathrm{ZnO}$ and relates the structure and thermal stability of the precursor complexes to the crystallinity and electrical conductivity of the zinc oxide.

Keywords: EISA, pore templating, pore size control, ligands, zinc oxide, conductivity.
\end{abstract}

\section{INTRODUCTION}

Zinc oxide is a wide bandgap $(\sim 3.3 \mathrm{eV})$ semiconductor with a large exciton binding energy ( $60 \mathrm{meV})$ [1] and unique optical, electrical and catalytic properties. $\mathrm{ZnO}$ can be used as transparent conductive oxide (TCO) in photovoltaic cells and displays [2], in photoluminescent [3-5] and in electroluminescent [6,7] devices such as light-emitting diodes. $\mathrm{ZnO}$ has been applied to construct nanocantilevers [8], piezoelectric generators for self-powered nano devices [9] and nanostructures with controlled thermal/electrical conductivity ratio [10]. The optical and photochemical properties of $\mathrm{ZnO}$ are exploited in photodetectors [11], photocatalyst [12] and gas sensors.

Many of these applications benefit from controlled nanostructuring of the $\mathrm{ZnO}$ material. The most obvious effect of a decrease in characteristic dimensions is the increases in specific surface area and in surface-to-volume ratio. In applications such as photocatalysis and gas sensing the increased surface area results in a higher number of accessible surface sites for chemisorption of e.g. $\mathrm{H}_{2}$ [13, 14], $\mathrm{O}_{2}$ [15], $\mathrm{NO}_{2}$ [16], $\mathrm{NH}_{3}$ [16] and ethanol $[17,18]$. However, a sufficiently high electrical conductivity has to be maintained to be able to detect the adsorption-induced resistivity changes.

Conductivity and nano-structure are also crucial for $\mathrm{ZnO}$ applications in dye-sensitized solar cells ${ }^{[19]}$. One approach is to use $\mathrm{ZnO}$ nanorod arrays as an electrode. However, the typical spacing $(\sim 100 \mathrm{~nm})$ between the rods is greater than the exciton diffusion length $(<10 \mathrm{~nm})$ $[20,21]$, which results in lower light harvesting efficiency.

\footnotetext{
*Corresponding author. Tel.: +49 30314 79371; fax: +49 3031422262.
} E-mail address: ralph.kraehnert@tu-berlin.de (R. Kraehnert)
For $\mathrm{TiO}_{2}$, the efficiency of dye sensitized solar cells increased significantly when the titania nanostructure was synthesized in the form of mesoporous films [22, 23], which provided a high surface area for contacting dye and electrode. However, for zinc oxide the synthesis of mesoporous films with concomitant control of pore size and electrical conductivity has not been reported so far.

The conductivity of the n-type semiconductor $\mathrm{ZnO}$ is closely related to its crystal structure. Crystal defects such as $\mathrm{Zn}$ interstitials and oxygen vacancies [1,24] can increase the materials electron conductivity. Moreover, the conductivity of nanocrystalline $\mathrm{ZnO}$ increases with crystallite size [25] explained by less contribution of potential barriers at grain boundaries. Also the introduction of shallow donors by photocatalytic decomposition of organic residues from the material synthesis can increase conductivity [26].

A synthetic strategy yielding metal oxide powders with high surface areas is Pechini's method [27] and variations thereof $[28,29]$. Here, a metal precursor and an organic acid form a complex in solution, which can be dried to a resin or gel. A subsequent thermal decomposition yields a nanocrystalline powder with high surface area and broad pore size distribution.

The pore size of mesoporous oxides can be controlled by so-called "nano-casting" or "templating". Mesoporous templated $\mathrm{ZnO}$ in the form of powders has been reported e.g. by Lepoutre et al. (F127 templated silica hard-template [30]), Wagner et al. (SBA-15 derived CMK-3 hardtemplate) [31] and Polarz et al. (F127, PAN-CMK-3 or CMK-1 templated) [32]. The soft-templated synthesis of mesoporous $\mathrm{ZnO}$ coatings with ordered pore structure was reported so far only by Eckhardt et al. [33]. The present contribution reports the synthesis of soft-templated mesoporous $\mathrm{ZnO}$ films with controlled crystallinity and electrical conductivity. 


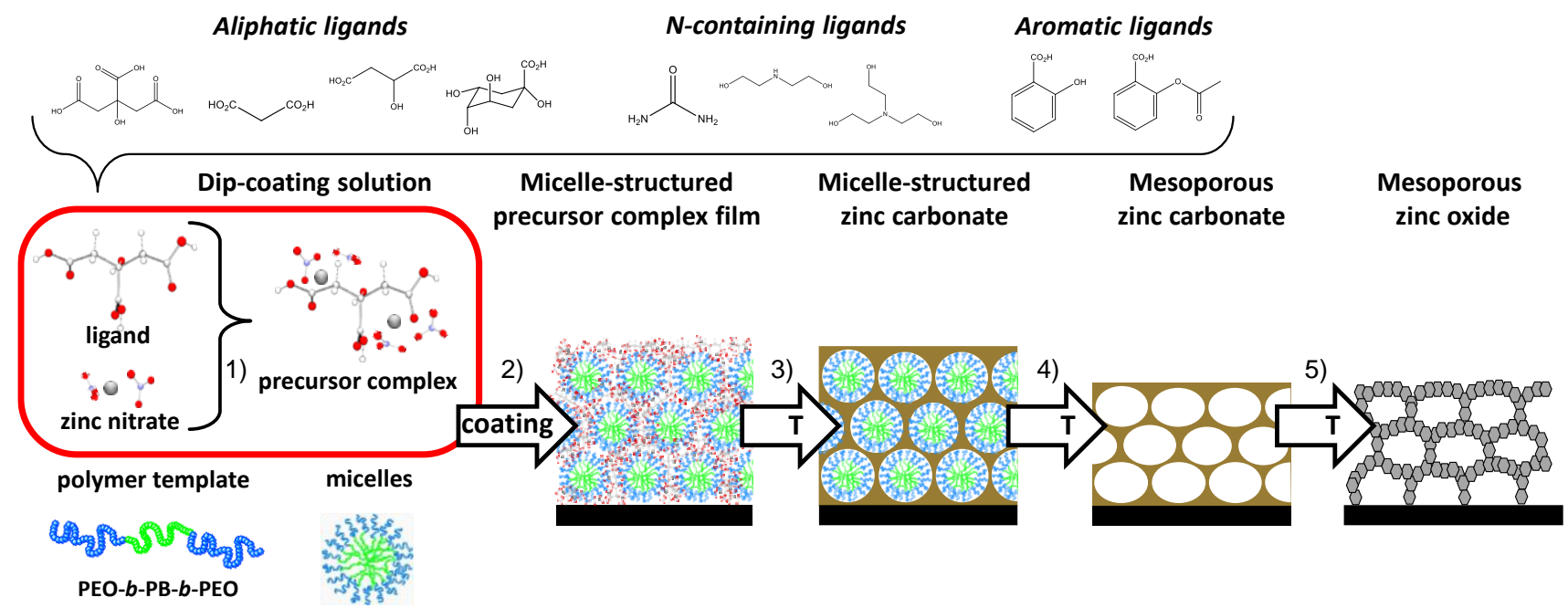

Fig. 1. Approach for the synthesis of mesoporous zinc oxide with micelle-controlled pore structure and ligand-controlled crystallinity and conductivity: 1) formation of a soluble precursor complex from zinc nitrate and the ligand; 2) film deposition and selfassembly of the micelles of the polymer template with the precursor complex into an ordered mesophase; 3) thermal decomposition of the precursor complex into a structurally stable zinc carbonate intermediate at low temperature while retaining the ordered mesophase; 4) thermal treatment to remove the polymer template resulting in open mesopores in the zinc carbonate film; 5) controlled decomposition of the carbonate into nanocrystalline zinc oxide

The synthesis approach is illustrated in Fig. 1. The synthesis relies on 1) the formation of a precursor complex between an organic ligand and $\mathrm{Zn}^{2+}$ ions, 2) the codeposition of the complex with micelles of an amphiphilic block-copolymer to form an ordered mesophase, 3) the thermal decomposition of the complex into the nanostructured zinc carbonate, 4) the thermal decomposition of the template polymer and 5) the conversion of the porous zinc carbonate into porous zinc oxide. We explore in particular the role of the ligand in the formation of the ordered carbonate phase and the resulting consequences in pore structure, crystallinity and conductivity of the formed mesoporous $\mathrm{ZnO}$.

In the first part of the paper, the control of the pore size by variation of the template is demonstrated. The thermal stability of complexes formed by different typical aliphatic, nitrogen-containing and aromatic ligands and tests their ability to form ordered mesophases and nanostructured carbonates is analysed in the second part. The third part analyses for the ligands that allow successful pore templating the pore structure, crystallinity and carbon content of the corresponding porous $\mathrm{ZnO}$. The last section assesses the electrical conductivity of the porous $\mathrm{ZnO}$ materials and relates it to material crystallinity and residual carbon content.

\section{EXPERIMENTAL}

\subsection{Chemicals}

Zinc nitrate hexahydrate $(98 \%)$ was purchased from Acros. The polymer templates of the structure poly(ethylene oxide)- $b$-poly(butadiene)- $b$-poly(ethylene oxide) with polymer block sizes $\mathrm{PEO}_{65}-\mathrm{PB}_{59}-\mathrm{PEO}_{65}$, $\mathrm{PEO}_{104}-\mathrm{PB}_{92}-\mathrm{PEO}_{104}$ and $\mathrm{PEO}_{213}-\mathrm{PB}_{184}-\mathrm{PEO}_{213}$ were synthesized by Polymer Service Merseburg $\mathrm{GmbH}$ as described in [34]. Ethanol (>99.9\%, absolute) was purchased from VWR. Citric acid (> $99.5 \%$ p.a.), DLmalic acid (>99\%), urea $(99.5 \%)$, triethanolamine
(> $99 \%$ ), salicylic acid (> $99 \%$, p.a.) and acetylsalicylic acid $(99 \%)$ were purchased from Roth. Zinc acetate dihydrate (>99.5\%), malonic acid (>99.5\%), D-(-)quinic acid (>98\%) and diethanolamine (99\%) were purchased from Alfa Aesar. All chemicals were used without further purification.

\subsection{Synthesis of mesoporous $\mathrm{ZnCO}_{3}$ and $\mathrm{ZnO}$ films}

Zinc oxide films were synthesized on Silicon wafers as well as glass plates (for conductivity measurements) via dip-coating and subsequent thermal treatments.

$\mathrm{Si}$ wafers were initially calcined for $2 \mathrm{~h}$ at $600^{\circ} \mathrm{C}$. Si wafers and glass plates were cleaned with ethanol prior to coating. Dip-coating solutions were prepared by dissolving the polymer template in ethanol / water solvent mixture by stirring overnight. Then, the respective ligand and zinc precursor were added and dissolved subsequently by stirring. Table 1 and ESI-S1 list the composition of the employed dip-coating solutions. The water content of the solution containing quinic acid had to be increased due to insufficient solubility. Dip-coating solutions were stable for about one week, while templating with older solutions typically failed. Dip-coating was performed in a Coater 5 (from IDLab s.r.o.) dipcoater with controlled atmosphere at a temperature of $25{ }^{\circ} \mathrm{C}$ and a relative humidity of $25 \%$ using a substrate withdrawal rate of $300 \mathrm{~mm} / \mathrm{min}$. Coated substrates were dried for ca. $10 \mathrm{~min}$ in the same atmosphere. In a typical synthesis, dried films were then heat-treated for $60 \mathrm{~min}$ at $250^{\circ} \mathrm{C}$ in a preheated oven, followed by $30 \mathrm{~min}$ at $400{ }^{\circ} \mathrm{C}$ in a preheated muffle furnace in an atmosphere of flowing air.

\subsection{Characterization}

Powder samples for thermogravimetric analysis were prepared by dissolving $\mathrm{Zn}\left(\mathrm{NO}_{3}\right)_{2} \cdot 6 \mathrm{H}_{2} \mathrm{O}$ and 1.0 molar equivalent of the respective ligand in an ethanol/water mixture, followed by drying for $24 \mathrm{~h}$ at $75^{\circ} \mathrm{C}$. 
Table 1. Composition of dip-coating solutions containing different ligands employed for the synthesis of micelletemplated mesoporous $\mathrm{ZnO}$ thin films

\begin{tabular}{|c|c|c|c|}
\hline Ligand & Zinc precursor & Template & Solvent \\
\hline \multicolumn{4}{|c|}{ Variation of the template } \\
\hline \multirow{3}{*}{$\begin{array}{c}\text { citric acid } \\
144 \mathrm{mg} ; \\
0.25 \mathrm{~mol} / \mathrm{L}\end{array}$} & \multirow{3}{*}{$\begin{array}{c}\mathrm{Zn}\left(\mathrm{NO}_{3}\right)_{2} \cdot \\
6 \mathrm{H}_{2} \mathrm{O} \\
444 \mathrm{mg} \\
0.5 \mathrm{~mol} / \mathrm{L}\end{array}$} & $\begin{array}{c}\mathrm{PEO}_{65}-\mathrm{PB}_{59}-\mathrm{PEO}_{65} \\
70 \mathrm{mg} ; 23 \text { 10-4 mol/L }\end{array}$ & \multirow{3}{*}{$\begin{array}{l}\text { Ethanol } \\
1.50 \mathrm{~mL} \\
\mathrm{H}_{2} \mathrm{O} \\
1.50 \mathrm{~mL}\end{array}$} \\
\hline & & $\begin{array}{l}\text { PEO }_{104-} \mathrm{PB}_{92}-\mathrm{PEO}_{104} \\
70 \mathrm{mg} ; 14 \text { 10-4 mol/L }\end{array}$ & \\
\hline & & $\begin{array}{l}\mathrm{PEO}_{213}-\mathrm{PB}_{184}-\mathrm{PEO}_{213} \\
70 \mathrm{mg} ; 7 \mathrm{10}-4 \mathrm{~mol} / \mathrm{L}\end{array}$ & \\
\hline \multicolumn{4}{|c|}{ Variation of the ligand } \\
\hline $\begin{array}{c}\text { citric acid } \\
144 \mathrm{mg} ; \\
0.25 \mathrm{~mol} / \mathrm{L}\end{array}$ & \multirow{4}{*}{$\begin{array}{c}\mathrm{Zn}\left(\mathrm{NO}_{3}\right)_{2} \cdot \\
6 \mathrm{H}_{2} \mathrm{O} \\
444 \mathrm{mg} \\
0.5 \mathrm{~mol} / \mathrm{L}\end{array}$} & \multirow{4}{*}{$\begin{array}{c}\mathrm{PEO}_{213}-\mathrm{PB}_{184}-\mathrm{PEO}_{213} \\
50 \mathrm{mg} ; 510-4 \mathrm{~mol} / \mathrm{L}\end{array}$} & \multirow{3}{*}{$\begin{array}{c}\text { Ethanol } \\
2.8 \mathrm{~mL} \\
\mathrm{H}_{2} \mathrm{O} \\
0.2 \mathrm{~mL}\end{array}$} \\
\hline $\begin{array}{c}\text { malonic acid } \\
78 \mathrm{mg} ; \\
0.25 \mathrm{~mol} / \mathrm{L} \\
\end{array}$ & & & \\
\hline $\begin{array}{c}\text { DL-malic acid } \\
101 \mathrm{mg} ; \\
0.25 \mathrm{~mol} / \mathrm{L} \\
\end{array}$ & & & \\
\hline $\begin{array}{c}\mathrm{D}(-) \text { quinic acid } \\
144 \mathrm{mg} ; \\
0.25 \mathrm{~mol} / \mathrm{L}\end{array}$ & & & $\begin{array}{c}\text { Ethanol } \\
1.85 \mathrm{~mL} \\
\mathrm{H}_{2} \mathrm{O} \\
1.15 \mathrm{~mL}\end{array}$ \\
\hline
\end{tabular}

For the ligands diethanolamin and triethanolamin, $\mathrm{Zn}(\mathrm{OAc})_{2} \cdot 2 \quad \mathrm{H}_{2} \mathrm{O}$ and 2.0 molar equivalents of ligand were used. TGA analysis was performed in a Seiko Instruments SSC/5200 TGDTA320 in air atmosphere with heating rates of $3 \mathrm{~K} / \mathrm{min}$ and $5 \mathrm{~K} / \mathrm{min}$.

SEM images were recorded with a JEOL 7401F field emission microscope at an acceleration voltage of $10 \mathrm{kV}$ and at a working distance of $4 \mathrm{~mm}$. Cross-section images were recorded of films on freshly split substrates. Image $\mathbf{J}$ Version 1.46r (http://imagej.nih.gov/ij) was employed to determine pore diameter, film thickness and to derive FFT plots from SEM images. EDX spectra were acquired at accelerating voltages of $2 \mathrm{kV}$ in gentle beam mode at a working distance of $12 \mathrm{~mm}$ using a BrukerQuantax 400 instrument attached to the SEM. SAXS measurements were performed at BESSY II, D71 source at PTB-Xray beamline with a in-vacuum Pilatus M1 detector at sampledetector distance of $3775 \mathrm{~mm}$ and X-ray energy of $8000.0 \mathrm{eV}$. XRD data were recorded on a Bruker D8 Advance instrument $(\mathrm{Cu}-\mathrm{K} \alpha$ radiation $)$ and gracing incident beam $\left(1^{\circ}\right)$. The surface conductivity of $\mathrm{ZnO}$ films coated on glass was measured with a home-made probe array of $8 \times 8$ gold pins in two points probe configuration at constant potential of $60 \mathrm{~V}$ during illumination with visible light from a Cree XP-G R5 LED (Fenix LD20, 180 lumen) with intensity maxima at $450 \mathrm{~nm}$ and $550 \mathrm{~nm}$ and an irradiance of $136 \mathrm{~W} / \mathrm{m}^{2}$ at the sample position.

\section{RESULTS AND DISCUSSION}

\subsection{Pore size control of templated mesoporous zinc oxide films}

The introduction of soft templated mesopores was reported in [33] for one block-copolymer template. Here, we report the control of the pore size by variation of the template. $\mathrm{ZnO}$ films were synthesized using PEO-b-PB-bPEO block-copolymer templates of different molecular sizes. The pore system of the resulting films was studied by SEM and SAXS (Fig. 2).Top-view SEM images show that for each template homogeneous $\mathrm{ZnO}$ films with spherically shaped mesopores are formed. The pore diameter is $8 \mathrm{~nm}$ for $\mathrm{PEO}_{65}-\mathrm{PB}_{59}-\mathrm{PEO}_{65}$ (Fig. 2 a), $15 \mathrm{~nm}$ for $\mathrm{PEO}_{104}-\mathrm{PB}_{92}-\mathrm{PEO}_{104}$ (Fig. 2 b) and $22 \mathrm{~nm}$ for $\mathrm{PEO}_{213^{-}}$ $\mathrm{PB}_{184}-\mathrm{PEO}_{213}$ (Fig. 2 c). Thus, pore size increases with increasing molecular size of the template.

2D SAXS patterns recorded at an incident angle of $90^{\circ}$ to the substrate show rings corresponding to periodical pore spacings in parallel to the substrate. At an incident angle of $6^{\circ}$ to the substrate, elliptical SAXS patterns indicate a film shrinkage perpendicular to the substrate. The patterns recorded with $90^{\circ} / 6^{\circ}$ incident angle correspond to periodic distances of $15 \mathrm{~nm} / 4 \mathrm{~nm}$ for $\mathrm{PEO}_{65}-$ $\mathrm{PB}_{59}-\mathrm{PEO}_{65}$ (Fig. $2 \mathrm{~d}, \mathrm{~g}$ ), $21 \mathrm{~nm} / 6 \mathrm{~nm}$ for $\mathrm{PEO}_{104}-\mathrm{PB}_{92}-$ $\mathrm{PEO}_{104}$ (Fig. $2 \mathrm{e}, \mathrm{h}$ ) and $38 \mathrm{~nm} / 19 \mathrm{~nm}$ for $\mathrm{PEO}_{213}-\mathrm{PB}_{184^{-}}$ $\mathrm{PEO}_{213}$ (Fig. $2 \mathrm{f}$, i). By increasing the pore, size also the pore spacings increases parallel and perpendicular to the substrate.

Comparison of $\mathrm{ZnO}$ films synthesized using PEO-bPB-b-PEO templates of different molecular sizes demonstrates that control of pore size can be achieved in the range of $8-22 \mathrm{~nm}$.

\subsection{Thermal stability of $\mathrm{Zn}$ complexes formed from different ligands}

The synthesis of mesoporous oxide films from complexed metal ions as outlined in [33] requires the formation of an intermediate mesoporous metal carbonate and its transformation into the crystalline metal oxide by thermal decomposition of the carbonate. Carbonate formation and carbonate decomposition have to occur in a temperature window that is compatible with the thermal decomposition behavior of the employed polymeric pore template.

The formation and decomposition of the required intermediate species $\mathrm{ZnCO}_{3}$ were assessed by thermogravimetric analysis of powder samples prepared from $\mathrm{Zn}^{2+}$ and different aliphatic, nitrogen-containing and aromatic complexing ligands. Fig. 3 presents the TGA curves of the respective complexes in comparison to the thermogram of the block-copolymer template PEO-b-PBDb-PEO.

The decomposition of the template polymer starts at $250^{\circ} \mathrm{C}$ and progresses more rapidly between 375 and $425^{\circ} \mathrm{C}$ (Fig. 3 a). A red dashed line marks the onset of polymer decomposition in Fig. 3.

All of the $\mathrm{Zn}$ complexes formed from citric acid (Fig. 3 b), malonic acid (Fig. 3 c), malic acid (Fig. 3 d) and quinic acid (Fig. 3 e) decompose in a similar fashion marked by an initial mass loss, a broad plateau at intermediate temperatures, a second pronounced mass loss and finally a stable mass.

The position of the plateau differs for the different ligands (citric acid: $180-320^{\circ} \mathrm{C}$, malonic acid $160-300{ }^{\circ} \mathrm{C}$, malic acid $150-340^{\circ} \mathrm{C}$, quinic acid 2 $20-380^{\circ} \mathrm{C}$ ). However, the plateau is in all cases at least $140 \mathrm{~K}$ wide. A previous study assigned this plateau for the case of $\mathrm{Zn}^{2+}$ complexed with citric acid to the formation and decomposition of an amorphous $\mathrm{Zn}$ carbonate phase [33]. It can thus be assumed that all of the four tested 
aliphatic ligands form a structurally stable zinc carbonate. However, the onset temperature of decomposition of the intermediate to $\mathrm{ZnO}$ differs depending on the ligand. The onset of carbonate decomposition is marked by a dashed line in Fig. 2 and subsequently used as a measure of the thermal stability of the respective precursor. A comparison between the thermal stability of the template polymer (Fig. 3 a) and the temperature at which the first mass loss occurs (Fig. $3 \mathrm{~b}-\mathrm{e}$ ) reveals that all studied $\mathrm{Zn}$ complexes with aliphatic ligands can form the carbonate phase before the template polymer starts to degrade.

All other tested $\mathrm{N}$-containing and aromatic ligands did not show such a favorable decomposition behavior that matches with the decomposition of the template polymer. The complex containing urea (Fig. $3 \mathrm{f}$ ) decomposes without a significant plateau. The complexes containing diethanolamine (Fig. $3 \mathrm{~g}$ ) and triethanolamine (Fig. $3 \mathrm{~h}$ ) decompose through a series of small plateaus. Conterosito et al. [35] studied the decomposition of similar triethanolamine complexes and did not observe intermediate formation of zinc carbonate. The conversion of the $\mathrm{N}$-containing ligand complexes into zinc carbonate is therefore unlikely. The complexes containing the aromatic ligands salicylic acid (Fig. 3 i) and acetylsalicylic acid (Fig. $3 \mathrm{j}$ ) exhibit small plateaus commencing at temperatures higher than the onset of template decomposition. Even if this could be ascribed to the formation of a carbonate intermediate, this intermediate forms at too high temperatures. At such temperatures the template polymer is already degraded. It can therefore not sustain the micelle-based nanostructure that is required for the formation of $\mathrm{ZnO}$ with templated mesoporosity. The thermal stability of the different precursor complexes can be related directly to their ability to form a micelletemplated mesoporous $\mathrm{ZnO}$ structure.
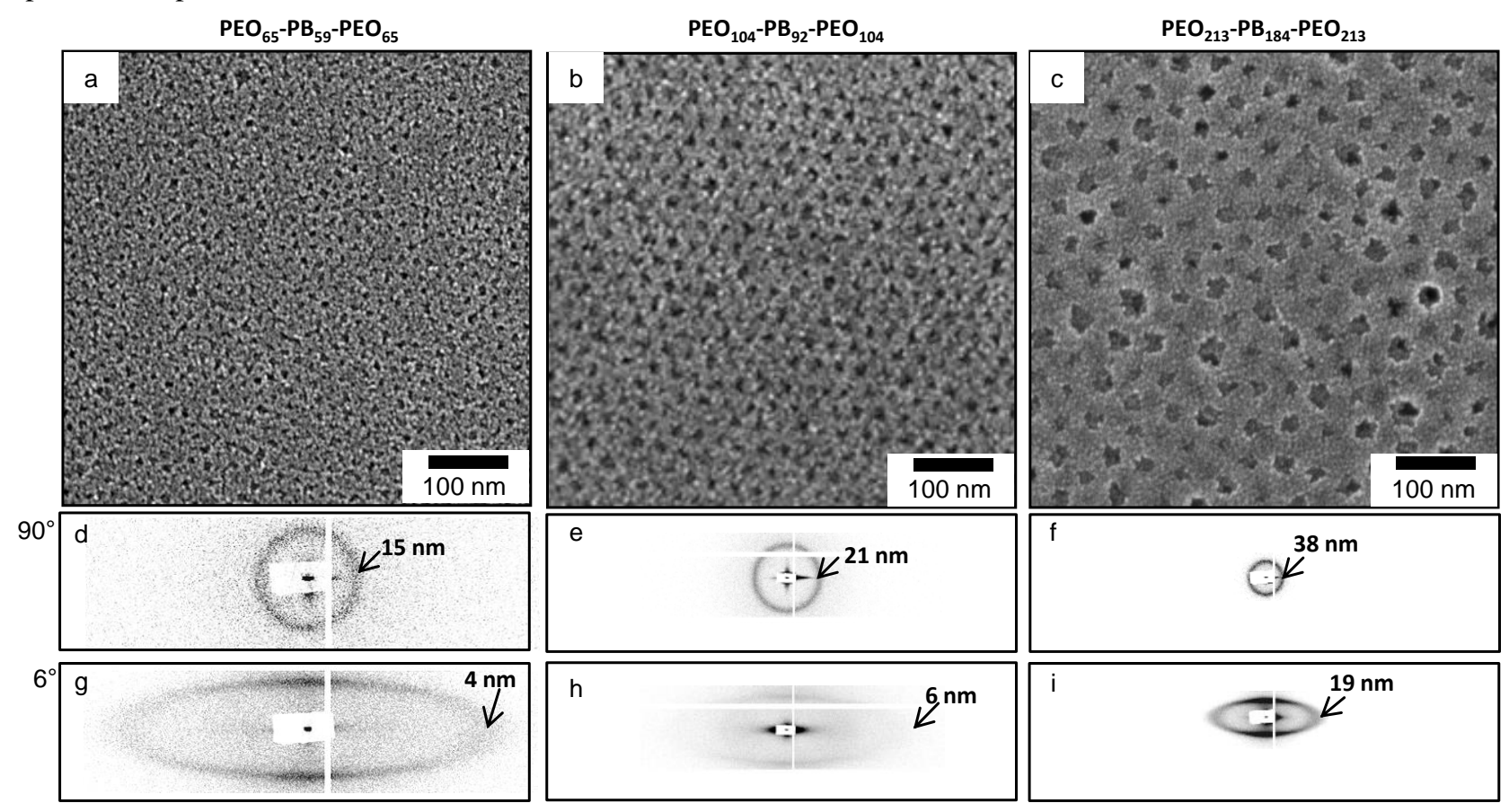

Fig. 2. Analysis of mesoporous $\mathrm{ZnO}$ films prepared using different pore templates by: a, b, c-SEM top-view images and $2 \mathrm{D}$ SAXS with incident angle of $\mathrm{d}, \mathrm{e}, \mathrm{f}-90^{\circ}$ and $\mathrm{g}, \mathrm{h}, \mathrm{i}-6^{\circ}$ to the substrate. All films were calcined first at $250^{\circ} \mathrm{C}(60$ min) followed by natural cooling to room temperature, followed by calcination at $400{ }^{\circ} \mathrm{C}\left(20\right.$ min for $\mathrm{PEO}_{65}-\mathrm{PB}_{59}-\mathrm{PEO}_{65}$ andPEO ${ }_{104}-\mathrm{PB}_{92}-\mathrm{PEO}_{104}$; $25 \mathrm{~min}$ for $\mathrm{PEO}_{213}-\mathrm{PB}_{184}-\mathrm{PEO}_{213}$ ) in static air. Variation in calcination time is to ensure the generation of smooth pore walls for small pores by small crystallites

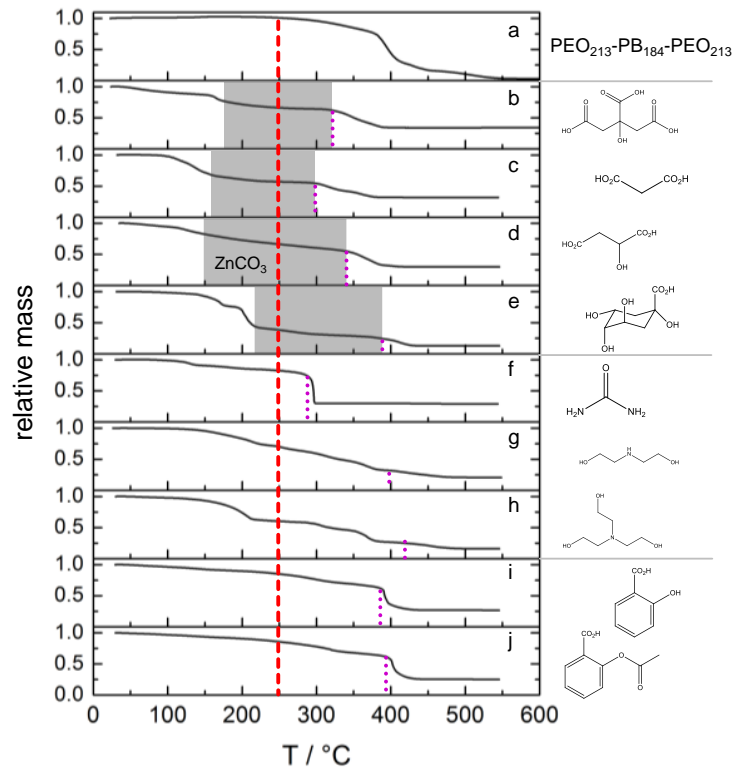

Fig. 3. Thermogravimetric analysis recorded for $a-$ the template polymer and $b-e$ the dried precursor complexes formed from $\mathrm{Zn}^{2+}$ with $\mathrm{b}-\mathrm{e}$ aliphatic ligands, $\mathrm{f}-\mathrm{h}$ nitrogencontaining ligands and $\mathrm{i}-\mathrm{j}$ aromatic ligands. Aliphatic ligands: $\mathrm{b}$-citric acid; $\mathrm{c}$-malonic acid; $\mathrm{d}$-malic acid and; e-quinic acid. N-containing ligands: $\mathrm{f}$-urea, $\mathrm{g}$-diethanolamine; $\mathrm{h}$-triethanolamine. Aromatic ligands: $\mathrm{i}$-salicylic acid; $\mathrm{j}$-acetylsalicylic acid. A vertical dashed line marks the onset of the decomposition of the template polymer $\left(250^{\circ} \mathrm{C}\right)$. Grey areas mark distinct plateaus that are assigned to the presence of an amorphous zinc carbonate. Dotted lines indicate the onset of the transformation into $\mathrm{ZnO}$. Samples were prepared by dissolution of $\mathrm{Zn}$ precursors $\left(\mathrm{Zn}\left(\mathrm{NO}_{3}\right)_{2}\right.$, except for $\mathrm{g}$ and $\mathrm{h}$ $\left.\left(\mathrm{Zn}(\mathrm{OAc})_{2}\right)\right)$ and ligand in water/ethanol mixtures, dried at $75^{\circ} \mathrm{C}$ and then heated with $5 \mathrm{~K} / \mathrm{min}(\mathrm{a}, \mathrm{b})$ or $3 \mathrm{~K} / \mathrm{min}(\mathrm{c}-$ j) in air. 
Despite numerous efforts to optimize the synthesis conditions, neither the nitrogen-containing nor the aromatic ligands were able to produce $\mathrm{ZnO}$ with templated pore structure (see ESI-S1 for synthesis conditions and SEM analysis of the $\mathrm{ZnO}$ morphology). In contrast, all the aliphatic ligands for which TGA indicated the formation of a metastable carbonate phase in the appropriate temperature window produced micelle-templated $\mathrm{ZnO}$ as shown in Fig. 4 a, c and e and discussed in detail below.

\subsection{Morphology and crystallinity of templated mesoporous zinc oxide films}

Since the ligand structure strongly influences the thermal stability of the precursor complex and the corresponding carbonate intermediate, significant differences are also expected in morphology and crystallinity of the respective mesoporous $\mathrm{ZnO}$ films. The $\mathrm{ZnO}$ films synthesized from $\mathrm{Zn}$ complexes of malonic acid, malic acid and quinic acid were therefore studied with respect to obtained morphology (SEM: Fig. $4 \mathrm{a}-\mathrm{f}$, TEM: ESI-S2) and crystallinity (XRD: Fig. 4 g; SAED: ESI-S3).

Fig. 4 shows SEM images in a/c/e top-view and b, d, f cross-section view along with fast fourier transformations (FFT) of the top-view images to assess local pore ordering (insets in Fig. 4 a, c, e) as well as X-ray diffractograms of each of the materials after calcination at $400^{\circ} \mathrm{C}$.
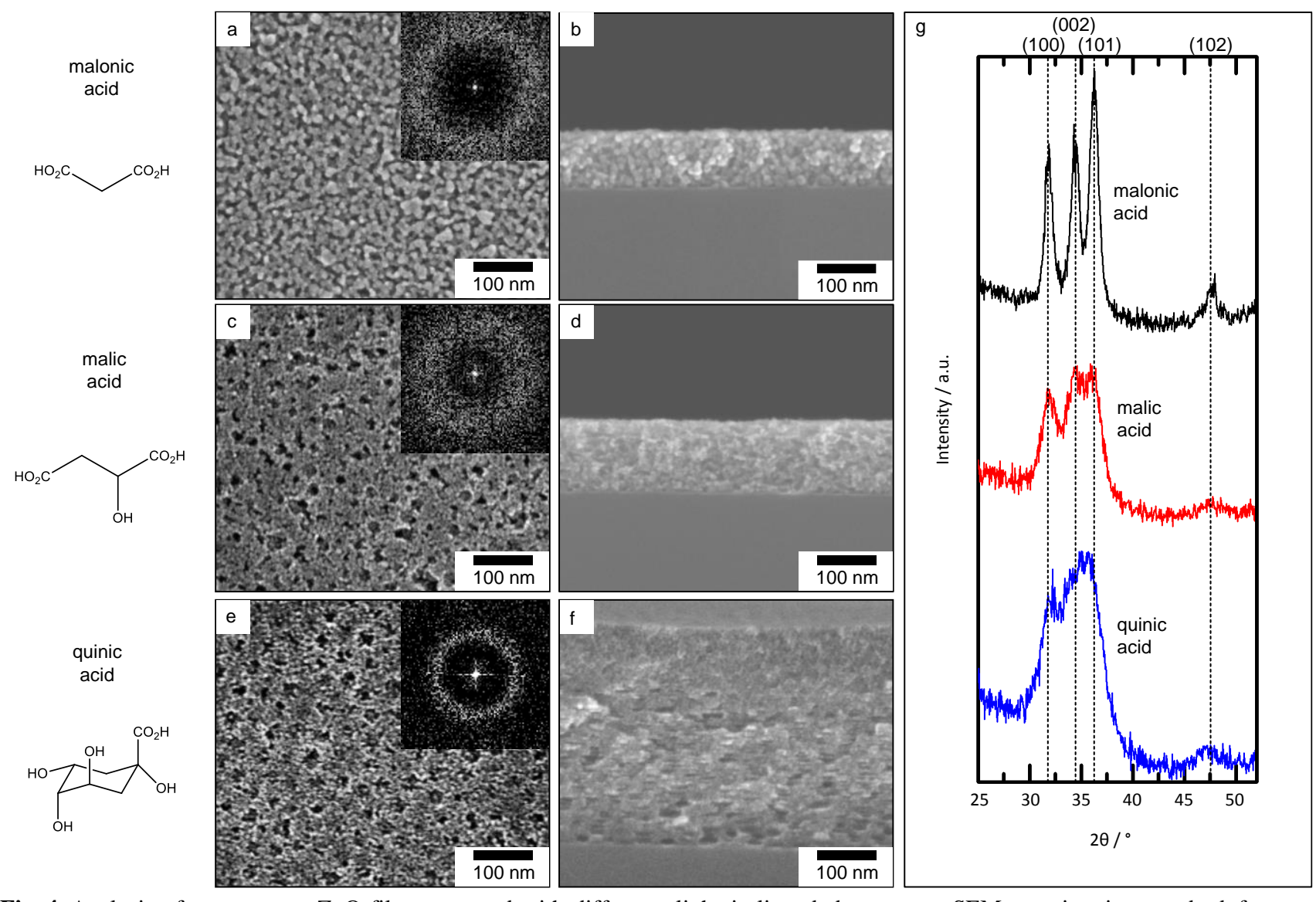

Fig. 4. Analysis of mesoporous $\mathrm{ZnO}$ films prepared with different aliphatic ligands by: a, c, e-SEM top-view images; b, d, $\mathrm{f}-\mathrm{cross}-$ section SEM images and $\mathrm{g}-\mathrm{X}$-ray diffraction. Insets in a, c, e-correspond to FFT transformations of the respective SEM image. Dashed lines in $\mathrm{g}$-correspond to literature data for $\mathrm{ZnO}$ in hexagonal zincite structure (PDF-No. 00-036-1451). Samples were prepared from dip-coating solutions containing $\mathrm{Zn}\left(\mathrm{NO}_{3}\right)_{2}$, the template polymer and either $\mathrm{a}, \mathrm{b}$-malonic acid, $\mathrm{c}, \mathrm{d}-$ malic or e, $\mathrm{f}$-quinic acid as complexing ligand. All films calcined first at $250{ }^{\circ} \mathrm{C}(60 \mathrm{~min})$ followed by natural cooling to room temperature, then $400{ }^{\circ} \mathrm{C}(30 \mathrm{~min})$ in static air
The top-view SEM images confirm that with all aliphatic ligands homogeneous $\mathrm{ZnO}$ films with micelletemplated regular pore structure are formed. The pores show a circular shape with narrow size distribution and diameters of $15 \pm 3 \mathrm{~nm}$ (malonic acid, Fig. 4 a), $17 \pm 3 \mathrm{~nm}$ (malic acid, Fig. 4 c) and $19 \pm 4$ nm (quinic acid, Fig. 4 e). circular pore shape is better defined for films malonic acid, nano crystals that constitute the pore walls. These crystals appear to be smaller for quinic acid than for malic acid and malonic acid (Fig. 4 a, c, e). HR-TEM analysis as presented in the supplement ESI-S2 confirms the presence of crystalline $\mathrm{ZnO}$ and the decrease in crystallite size in the malonic (ESI-S2a) to malic (ESI-S2b) and quinic crystalli-S2). Both phase composition and the trend in and selected-area electron diffraction (see Supplement ESI-S3). All three films show only reflections that clearly correspond to $\mathrm{ZnO}$ in the hexagonal zincite structure in XRD (Fig. 4 g, PDF-No. 00-036-1451 reflection positions are marked with dashed lines) as well as SAED (ESI$\mathrm{S} 3 \mathrm{a}, \mathrm{b}, \mathrm{c})$. Evaluation of the FWHM with Rietveld crystallite sizes of $4 \mathrm{~nm}$ (quinic acid), $5 \mathrm{~nm}$ (malic acid) and about $9 \mathrm{~nm}$ (malonic acid). crystallite [36] and Scherrer equation [37] yields 
Hence, aliphatic ligands and complexes with higher thermal stability result in smaller $\mathrm{ZnO}$ crystallites. The presence of an ordered pore structure is indicated for all three films by rings visible in the FFT of the respective top-view SEM images (insets in Fig. 4 a, c, e). The ring is better defined for the material with smaller crystallites synthesized from quinic acid. The ring diameter is indicative of the periodic spacing between the pores and shows the highest periodic distance for films synthesized from quinic acid $(37 \mathrm{~nm})$ when compared to malic acid $(30 \mathrm{~nm})$ and malonic acid $(25 \mathrm{~nm})$. SAXS was measured and is shown in ESI-S4. Periodic distances correspond to $37 \mathrm{~nm}$ (quinic acid), $27 \mathrm{~nm}$ (malic acid) and $25 \mathrm{~nm}$ (malonic acid). Both pore size and pore spacing appear to scale with the molecular mass of the complexing ligand molecule. This observation can be rationalized by the fact that (for the same molecular ratio between amount of template polymer and precursor complex) the larger ligand molecules increase the carbon content in the initial $\mathrm{Zn}$ complex, which results in thicker pore walls in the deposited mesophase and correspondingly a larger spacing between micelles and pores. Cross-section SEM images show elliptical mesopores throughout the film volume. This effect is typically observed for micelle-templated metal oxide films and can be attributed to the shrinkage of films in the direction perpendicular to the substrate during calcination [38-40]. The obtained film thickness scales with the size of the ligand molecule (malonic acid $95 \mathrm{~nm}$, Fig. 4 b; malic acid 125 nm, Fig. 4 d; quinic acid $370 \mathrm{~nm}$, Fig. 4 e), which is a consequence of the increasing viscosity of the respective dip-coating solutions.

The comparison of the films suggests that film morphology and crystallinity are strongly influenced by the properties of the (aliphatic) ligand molecule that forms the precursor complex. Ligand molecules with a higher thermal stability result in smaller $\mathrm{ZnO}$ crystallites, which in turn assemble into smoother pore walls with better defined pore shape. Larger ligands with higher carbon content increase the spacing of the mesopores as well as the film thickness.

\subsection{Relationships between residual carbon content, crystallinity and conductivity}

The electrical conductivity of $\mathrm{ZnO}$ is a critical parameter for many of its applications. The conductivity of metal oxides is typically influenced by its crystallinity. In order to unravel the relations between precursor composition, carbonate decomposition and $\mathrm{ZnO}$ crystallinity, Fig. 5 plots for the mesoporous $\mathrm{ZnO}$ film prepared from each ligand $\mathrm{a}$-the amount of residual carbon (from EDX), b - the respective $\mathrm{ZnO}$ crystallite size (from XRD) and $\mathrm{c}$-the corresponding electrical conductivity vs. the onset temperature of the transformation of the carbonate intermediate into zinc oxide.

Fig. $5 \mathrm{a}$ indicates that the content of carbon that remains in the calcined $\mathrm{ZnO}$ film is directly related to the thermal stability of the $\mathrm{ZnCO}_{3}$ intermediate formed from the respective $\mathrm{Zn}$ precursor complex. Higher temperatures at which the zinc carbonate decomposes into zinc oxide yield a higher content of residual carbon (for films calcined at identical conditions). Quinic acid, the ligand molecule with the highest number of $\mathrm{C}$ atoms retains also the highest amount of carbon. The retained amount of carbon directly influences the size of the formed $\mathrm{ZnO}$ crystallites (Fig. 5 b). The obtained crystallite size ranges from ca. $9 \mathrm{~nm}$ (malonic acid) to about $4 \mathrm{~nm}$ (quinic acid). A larger amount of retained carbon therefore delays the crystallization and forms finer grains when compared at identical calcination conditions.

The electrical conductivity of the different $\mathrm{ZnO}$ films scales in an analogous fashion (Fig. 5 c). The mesoporous $\mathrm{ZnO}$ film with the smallest grain size, i.e. the one synthesized with the complex with quinic acid, exhibits the lowest conductivity. Two effects can contribute to this observation. Smaller crystallites lead to an increase in the number of grain boundaries that charge carriers have to pass.

Moreover, the residual carbon possibly accumulates at the formed grain boundaries increasing the potential energy barrier at the grain boundaries. The highest electrical conductivity is therefore obtained with the ligand that has the lowest number of $\mathrm{C}$ atoms, resulting in the lowest amount of retained carbon and the largest crystallite size in the respective film, i.e. malonic acid. A higher carbon content increases the resistance of the mesoporous $\mathrm{ZnO}$ against sintering of the pore walls, but at the cost of a lower electrical conductivity.
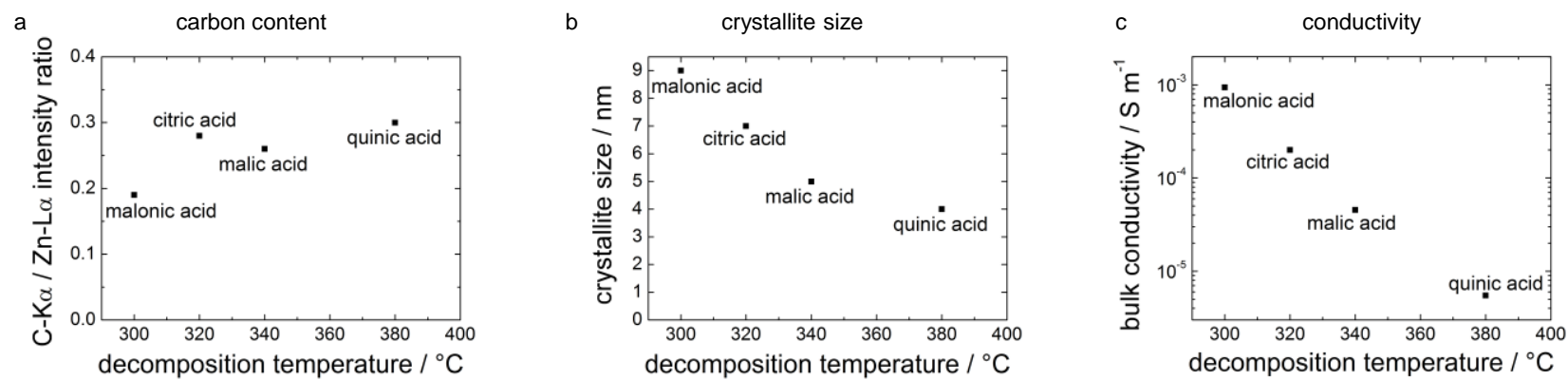

Fig. 5. Analysis of mesoporous $\mathrm{ZnO}$ films prepared with different aliphatic ligands with respect to $\mathrm{a}-$ residual carbon content; $\mathrm{b}-$ crystallite size; c-electrical conductivity. a-carbon content expressed as intensity ratio between C-K $\alpha$ and $\mathrm{Zn}$ - $\mathrm{L} \alpha$ lines (from EDX); $b$-crystallite size (from XRD and Scherrer equation/Rietveld refinement); $c$-electrical bulk conductivity (from surface conductivity measurement divided by film thickness from cross-section SEM images). All data are plotted vs. the decomposition temperature of the respective carbonate intermediate (from TGA, see Fig. 2). All data measured for $\mathrm{ZnO}$ films on Si substrates except for c) conductivity (glass substrate) for films calcined at $250{ }^{\circ} \mathrm{C}(60 \mathrm{~min})$ followed by $400{ }^{\circ} \mathrm{C}(30 \mathrm{~min})$ 
The conductivity measured for the presented mesoporous $\mathrm{ZnO}$ films agrees within a factor of 20 with literature data that were reported for zinc oxide prepared without templated porosity and without additional reducing or defect-inducing treatments. $\mathrm{ZnO}$ thin films with average grain size of $\sim 35 \mathrm{~nm}$ synthesized by Carcia et al. [24] via rf magnetron sputtering in the presence of $10^{-5}$ torr oxygen conducted with ca. $10^{-4} \mathrm{~S} \mathrm{~m}^{-1}$. A similar conductivity $\left(10^{-3}\right.$ to $10^{-4} \mathrm{~S} \mathrm{~m}^{-1}$ ) was reported by Bae et al. [41] for $\mathrm{ZnO}$ thin films (grain size $\sim 100 \mathrm{~nm}$ ) prepared by spincoating mixtures of zinc acetate, isopropanol and diethanolamine followed by calcination at $800{ }^{\circ} \mathrm{C}$. A similar synthesis by Caglar et al. [42] (zinc acetate, 2-methoxethanol, monoethanolamine, $550{ }^{\circ} \mathrm{C}$ ) yielded $\mathrm{ZnO}$ films with a conductivity of $5 \cdot 10^{-5} \mathrm{~S} \mathrm{~m}^{-1}$. Berber et al. [25] reported a conductivity of about $\sim 1.2 \cdot 10^{-2} \mathrm{~S} \mathrm{~m}^{-1}$ for $\mathrm{ZnO}$ nano particles of about $8 \mathrm{~nm}$ size spin-coated onto Corning glass. Annealing the films in air at $550{ }^{\circ} \mathrm{C}$ increased the crystallite size to ca. $80 \mathrm{~nm}$ and the conductivity to $\sim 2.2 \cdot 10^{-2} \mathrm{~S} \mathrm{~m}^{-1}$, confirming our observation that larger $\mathrm{ZnO}$ crystals result in improved electrical conductivity.

\section{CONCLUSIONS}

Zinc oxide films with ordered mesopore structure and tuneable crystallinity and electrical conductivity can be prepared by dip-coating of solutions containing an amphiphilic block copolymer and complexes of $\mathrm{Zn}^{2+}$ ion with aliphatic ligands. The obtained pore structure is controlled by the template polymer. The pore size was controlled in the range of $8-22 \mathrm{~nm}$ by using templates of different molecular sizes. The aliphatic ligand controls the crystallinity and conductivity of the pore walls. Depending on the ligands structure, the complexes transform during heat-treatment into amorphous carbonates with different thermal stabilities. A higher thermal stability results after calcination at $400{ }^{\circ} \mathrm{C}$ in an increased content of residual carbon and smaller $\mathrm{ZnO}$ crystals that constitute the pore walls. The materials electrical conductivity decreases with decreasing crystallite size.

Ligands other than aliphatic compounds (nitrogen containing or aromatic compounds) were not able to form the amorphous zinc carbonate in a temperature window that is compatible with the removal of the pore template. Accordingly, no micelle-templated mesoporous $\mathrm{ZnO}$ was obtained with these complexes, which further supports the proposed synthesis mechanism (Fig. 1).

Thermogravimetric analysis of the precursor complex proves to be an efficient and simple tool to probe the suitability of the ligand for the $\mathrm{ZnO}$ synthesis.

A further increase in $\mathrm{ZnO}$ conductivity could be realized applying procedures reported in literature, e.g. the photocatalytic removal of carbon residues ${ }^{[26]}$, reductive treatments ${ }^{[10]}$ or doping. Moreover, the developed approach allows the facile control of pore structure, crystallinity and conductivity. It could therefore serve as a tool for device production and for the synthesis of model system for the assessment of structure-activity relationships in catalytic, photo-catalytic, gas sensing, TCO and solar-cell applications.

\section{Acknowledgement}

This work is part of the Cluster of Excellence "Unifying Concepts inCatalysis" coordinated by the Technische Universität Berlin. Financial support by the Deutsche Forschungsgemeinschaft (DFG) within the framework ofthe German Initiative for Excellence is gratefully acknowledged (EXC 314). The authors acknowledge ZELMI at Technical University Berlin for support in TEM analysis. Armin Hoell, Eike Gericke and the PTB are acknowledged for support in SAXS measurements. Arno Bergmann is acknowledged for support in Rietveld refinement. R.K. thanks in particular Einstein Foundation Berlin for generous support provided by an Einstein-Junior-Fellowship (EJF-2011-95). D.B., B.E. and R.K. acknowledge additional funding from BMBF (FKZ 03EK3009). R.S. acknowledges financial support by the Berlin Graduate school of Natural Sciences and Engineering (BIG-NSE).

\section{REFERENCES}

1. Özgür, Ü., Alivov, Y.I., Liu, C., Teke, A., Reshchikov, M.A., Doan, S., Avrutin, V., Cho, S.J., Morkoc, H. A Comprehensive Review of $\mathrm{ZnO}$ Materials and Devices Journal of Applied Physics 98 (4) 2005: pp. 041301-1-04301-103.

2. Gordon, R.G. Criteria for Choosing Transparent Conductors MRS Bulletin 25 (08) 2000: pp. $52-57$.

3. Lin, Y., Xie, J., Wang, H., Li, Y., Chavez, C., Lee, S., Foltyn, S.R., Crooker, S.A., Burrell, A.K., McCleskey, T.M., Jia, Q. X. Green Luminescent Zinc Oxide Films Prepared by Polymer-Assisted Deposition with Rapid Thermal Process Thin Solid Films 492 2005: pp. 101-104.

4. Studenikin, S.A., Golego, N., Cocivera, M. Fabrication of Green and Orange Photoluminescent, Undoped $\mathrm{ZnO}$ Films Using Spray Pyrolysis Journal of Applied Physics 84 (4) 1998: pp. $2287-2294$ http://dx.doi.org/10.1063/1.368295

5. Yu, W.D., Li, X.M., Gao, X.D. Self-Catalytic Synthesis and Photoluminescence of $\mathrm{ZnO}$ Nanostructures on ZnO Nanocrystal Substrates Applied Physics Letters 84 (14) 2004: pp. $2658-2660$ http://dx.doi.org/10.1063/1.1695097

6. Könenkamp, R., Word, R.C., Godinez, M. Ultraviolet Electroluminescence from ZnO/Polymer Heterojunction Light-Emitting Diodes Nano Letters 5(10) 2005: pp. $2005-2008$.

http://dx.doi.org/10.1021/n1051501r

7. Park, W.I., Yi, G.C. Electroluminescence in n-ZnO Nanorod Arrays Vertically Grown on $\mathrm{p}-\mathrm{GaN}$ Advanced Materials 16 (1) 2004: pp. 87-90. http://dx.doi.org/10.1002/adma.200305729

8. Bai, X.D., Gao, P.X., Wang, Z.L., Wang, E.G. Dual-Mode Mechanical Resonance of Individual $\mathrm{ZnO}$ Nanobelts Applied Physics Letters 82 (26) 2003: pp. 4806-4808. http://dx.doi.org/10.1063/1.1587878

9. Wang, Z.L., Song, J. Piezoelectric Nanogenerators Based on Zinc Oxide Nanowire Arrays Science 312 (5771) 2006: pp. 242-246.

10. Hong, M.H., Park, C.S., Shin, S., Cho, H.H., Seo, W.S., Lim, Y.S., Lee, J.K., Park, H.H. Effect of Surfactant Concentration Variation on the Thermoelectric Properties of Mesoporous ZnO Journal of Nanomaterials 2013 2013: pp. 172504-1-172504-6.

11. Law, J.B.K., Thong, J.T.L. Simple Fabrication of a $\mathrm{ZnO}$ Nanowire Photodetector with a Fast 
Photoresponse Time Applied Physics Letters

88 (13) 2006: pp. 133114-1-133114-3.

12. Kuo, T.J., Lin, C.N., Kuo, C.L., Huang, M.H. Growth of Ultralong $\mathrm{ZnO}$ Nanowires on Silicon Substrates by Vapor Transport and Their Use as Recyclable Photocatalysts Chemistry of Materials 19 (21) 2007: pp. 5143-5147.

13. Rout, C.S., Raju, A.R., Govindaraj, A., Rao, C.N.R. Hydrogen Sensors Based on ZnO Nanoparticles Solid State Communications 138 (3) 2006: pp. 136-138. http://dx.doi.org/10.1016/j.ssc.2006.02.016

14. Wang, H.T., Kang, B.S., Ren, F., Tien, L.C., Sadik, P.W., Norton, D.P., Pearton, S.J., Lin, J. Hydrogen-Selective Sensing at Room Temperature with $\mathrm{ZnO}$ Nanorods Applied Physics Letters 86 (24) 2005, 243503-1-243503-3.

15. Fan, Z., Wang, D., Chang, P.C., Tseng, W.Y., Lu, J.G. ZnO Nanowire Field-Effect Transistor and Oxygen Sensing Property Applied Physics Letters 85 (24) 2004: pp. 5923 - 5925.

16. Fan, Z., Lu, J.G. Gate-Refreshable Nanowire Chemical Sensors Applied Physics Letters 86 (12) 2005: pp. 123510-1-123510-3.

17. Wan, Q., Li, Q.H., Chen, Y.J., Wang, T.H., He, X.L., Li, J.P., Lin, C.L. Fabrication and Ethanol Sensing Characteristics of ZnO Nanowire Gas Sensors Applied Physics Letters 84 (18) 2004: pp. 3654-3656.

http://dx.doi.org/10.1063/1.1738932

18. Xiangfeng, C., Dongli, J., Djurisic, A.B., Leung, Y.H. GasSensing Properties of Thick Film Based on ZnO Nano-Tetrapods Chemical Physics Letters 401 2005: pp. 426-429.

http://dx.doi.org/10.1016/j.cplett.2004.11.091

19. Schmidt-Mende, L., MacManus-Driscoll, J. L. $\mathrm{ZnO}-$ Nanostructures, Defects, and Devices Materials Today 10 (5) 2007: pp. $40-48$. http://dx.doi.org/10.1016/S1369-7021(07)70078-0

20. Peiro, A. M., Ravirajan, P., Govender, K., Boyle, D. S., O'Brien, P., Bradley, D. D. C., Nelson, J., Durrant, J. R. Hybrid Polymer/Metal Oxide Solar Cells Based on $\mathrm{ZnO}$ Columnar Structures Journal of Materials Chemistry 16 (21) 2006: pp. $2088-2096$. http://dx.doi.org/10.1039/b602084d

21. Ravirajan, P., Peiro, A. M., $\quad$ Nazeeruddin, M. K., Graetzel, M., Bradley, D. D. C., Durrant, J. R., Nelson, J. Hybrid Polymer/Zinc Oxide Photovoltaic Devices with Vertically Oriented $\mathrm{ZnO}$ Nanorods and an Amphiphilic Molecular Interface Layer Journal of Physical Chemistry B 110 (15) 2006: pp. 7635-7639.

22. Coakley, K. M., McGehee, M. D. Photovoltaic Cells Made from Conjugated Polymers Infiltrated into Mesoporous Titania Applied Physics Letters 83 (16) 2003: pp. 3380-3382.

23. Zukalova, M., Zukal, A., Kavan, L., Nazeeruddin, M. K., Liska, P., Gratzel, M. Organized Mesoporous TiO2 Films Exhibiting Greatly Enhanced Performance in Dye-Sensitized Solar Cells Nano Letters 5 (9) 2005: pp. 1789-1792.

24. Carcia, P. F., $\quad$ McLean, R. S., $\quad$ Reilly, M. H., $\quad$ Nunes, G. Transparent ZnO Thin-Film Transistor Fabricated by rf Magnetron Sputtering Applied Physics Letters 82 (7) 2003: pp. $1117-1119$. http://dx.doi.org/10.1063/1.1553997

25. Berber, M., Bulto, V., Kliss, R., Hahn, H. Transparent Nanocrystalline ZnO Films Prepared by Spin Coating Scripta Materialia 53 (5) 2005: pp. 547-551.

26. Wagata, H., Ohashi, N., Katsumata, K.-i., $\quad$ Segawa, H., Wada, Y., $\quad$ Yoshikawa, H., $\quad$ Ueda, S., $\quad$ Okada, K., Matsushita, N. An Aqueous Solution Process and Subsequent UV Treatment for Highly Transparent Conductive ZnO Films Journal of Materials Chemistry 22 (38) 2012: pp. 20706-20712.
27. Pechini, M.P., Method of Preparing Lead and Alkaline Earth Titanates and Niobates and Coating Method. U.S. Patent 3330697, 1967.

28. Bluthardt, C., $\quad$ Fink, C., $\quad$ Flick, K., $\quad$ Hagemeyer, A., Schlichter, M., Volpe, A.,Jr. Aqueous Synthesis of High Surface Area Metal Oxides Catalysis Today 137 (1) 2008: pp. $132-143$.

29. Farbun, I.A., Romanova, I.V., Kirillov, S.A. Optimal Design of Powdered Nanosized Oxides of High Surface Area and Porosity Using a Citric Acid Aided Route, with Special Reference to $\mathrm{ZnO}$ Journal of Sol-Gel Science and Technology 68 (3) 2013: pp. $411-422$. http://dx.doi.org/10.1007/s10971-013-3024-7

30. Lepoutre, S., Julian-Lopez, B., Sanchez, C., Amenitsch, H., Linden, M., Grosso, D. Nanocasted Mesoporous Nanocrystalline ZnO Thin Films Journal of Materials Chemistry 20 (3) 2009: pp. 537-542. http://dx.doi.org/10.1039/B912613A

31. Wagner, T., Waitz, T., Roggenbuck, J., $\quad$ Froba, M., Kohl, C.D., Tiemann, M. Ordered Mesoporous $\mathrm{ZnO}$ for Gas Sensing Thin Solid Films 515 (23) 2007: pp. 8360-8363. http://dx.doi.org/10.1016/j.tsf.2007.03.021

32. Polarz, S., Orlov, A.V., Schueth, F., Lu, A.H. Preparation of High-Surface-Area Zinc Oxide with Ordered Porosity, Different Pore Sizes, and Nanocrystalline Walls Chemistry-a European Journal 13 (2) 2007: pp. 592-597.

33. Eckhardt, B., $\quad$ Ortel, E., $\quad$ Bernsmeier, D., Polte, J., Strasser, P., Vainio, U., Emmerling, F., Kraehnert, R. Micelle-Templated Oxides and Carbonates of Zinc, Cobalt, and Aluminum and a Generalized Strategy for Their Synthesis Chemistry of Materials 25 (14) 2013: pp. 2749-2758.

34. Ortel, E., $\quad$ Fischer, A., $\quad$ Chuenchom, L., $\quad$ Polte, J., Emmerling, F., Smarsly, B., Kraehnert, R. New Triblock Copolymer Templates, PEO-PB-PEO, for the Synthesis of Titania Films with Controlled Mesopore Size, Wall Thickness, and Bimodal Porosity Small 8 (2) 2012: pp. 298-309.

35. Conterosito, E., Croce, G., Palin, L., $\quad$ Boccaleri, E., van Beek, W., Milanesio, M. Crystal Structure and Solid-State Transformations of $\mathrm{Zn}$-Triethanolamine-Acetate Complexes to $\mathrm{ZnO}$ Crystengcomm 14 (13) 2012: pp. 4472-4477.

36. Rietveld, H.M. A Profile Refinement Method for Nuclear and Magnetic Structures Journal of Applied Crystallography 2 1969: pp. $65-71$.

37. Patterson, A.L. Scherrer Formula for X-Ray Particle Size Determination Physical Review 56 1939: pp.978-982. http://dx.doi.org/10.1103/PhysRev.56.978

38. Brinker, C.J., Lu, Y., Sellinger, A., Fan, H. EvaporationInduced Self-Assembly: Nanostructures Made Easy Advanced Materials 11 (7) 1999: pp. 579-585.

39. Eckhardt, B., $\quad$ Ortel, E., $\quad$ Polte, J., Bernsmeier, D., Goerke, O., Strasser, P., Kraehnert, R. Micelle-Templated Mesoporous Films of Magnesium Carbonate and Magnesium Oxide Advanced Materials 24 (23) 2012: pp. 3115-3119.

40. Sanchez, C., Boissière, C., Grosso, D., Laberty, C., Nicole, L. Design, Synthesis, and Properties of Inorganic and Hybrid Thin Films Having Periodically Organized Nanoporosity Chemistry of Materials 20 (3) 2008: pp. 682-737.

41. Youl Bae, H., Man Choi, G. Electrical and Reducing Gas Sensing Properties of $\mathrm{ZnO}$ and $\mathrm{ZnO}-\mathrm{CuO}$ Thin Films Fabricated by Spin Coating Method Sensors and Actuators B: Chemical 55 (1) 1999: pp. 47-54.

42. Caglar, M., Ilican, S., Caglar, Y., Yakuphanoglu, F. Electrical Conductivity and Optical Properties of $\mathrm{ZnO}$ Nanostructured Thin Film Applied Surface Science 255 (8) 2009: pp. $4491-4496$. http://dx.doi.org/10.1016/j.apsusc.2008.11.055 